\title{
MORCEGOS URBANOS: A CONEXÃO ESCOLA-SOCIEDADE NA BUSCA DA CONSTRUÇÃO DO CONHECIMENTO TÉCNICO- CIENTÍFICO
}

\author{
URBAN BATS: A SCHOOL-SOCIETY CONNECTION IN SEARCH OF BUILDING \\ TECHNICAL-SCIENTIFIC KNOWLEDGE
}

DOI: $10.23926 / R P D .2526-2149.2020 . v 5 . n 3 . p 1717-1732 . i d 822$

\author{
Sérgio Gomes da Silva \\ Mestre em Ecologia e \\ Conservação (UNEMAT) \\ Doutorando em Ciências \\ Ambientais (UNEMAT) \\ Professor na Instituição \\ (IFMT).
}

sergiogomes_bats@yahoo.co $\underline{\text { m.br }}$

\section{Francimeire}

Fernandes Ferreira

Mestre em Ciências

Ambientais (UNEMAT)

Doutoranda em Ecologia e

Conservação (UNEMAT)

Pesquisadora Colaboradora

(IFMT).

ferreira.francimeire@yahoo. com.br

\section{Jéssica da Silva Polizei \\ Técnica em Administração \\ (IFMT) \\ jessica.polizei@hotmail.com}

\section{Jonas Aguiar Lago}

Técnico em Química (IFMT)

Graduando em Licenciatura

em Física (IFMT)

Assistente de Laboratório

(IFMT).

jonas.lago@plc.ifmt.edu.br
Resumo: As ações que envolvem a conexão escola-sociedade são um desafio nos tempos atuais. Mas devem ser implantadas, pois ambientes educacionais possuem profissionais diversos que podem auxiliar gestões públicas limitadas em poder suprir as necessidades de formação de seus colaboradores. Entre órgãos da gestão pública municipal, estão os agentes de saúde, que tendem a possuir conhecimento técnico limitado para atuarem em suas atividades. Nosso objetivo foi promover a conexão escola-sociedade com realização de capacitação técnica-científica para profissionais da saúde do município de Pontes e Lacerda, Mato Grosso, Brasil, sobre os morcegos urbanos. A metodologia contou com organograma prévio que incluíram ações de elaboração do material, realização da capacitação e retroalimentação para ver os resultados do processo. Os resultados denotam aspectos positivos e tornam os agentes atuantes e replicadores de conhecimento. Ações com esse intuito agregam conhecimentos para ampliar o rol de atuação no processo de atenção à saúde do município sobre a temática morcegos.

Palavras-chave: Capacitação. Agente de Saúde. Educação. Informação.

\begin{abstract}
The actions that involve the school-society connection are a challenge today. But they must be implemented, since educational environments have different professionals who can assist public administrations limited in being able to supply the training needs of their employees. Among municipal public management bodies, there are health agents, who tend to have limited technical knowledge, to act in their activities. Our objective was to promote the schoolsociety connection with technical and scientific training, for health professionals in the municipality of Pontes e Lacerda, Mato Grosso, Brazil, on urban bats. The methodology had a previous organization chart, which included actions for preparing the material carrying out the training and feedback to see the results of the process. The results denote positive aspects, and make agents active and replicators of knowledge Actions with this aim add knowledge to expand the role of action in the health care process of the municipality on the theme of bats.
\end{abstract}

Keywords: Training. Health Agent. Educacion. Information. 


\section{INTRODUÇÃO}

A conexão escola-sociedade precisa se fortalecer no âmbito de promover um processo construtivo, entre troca de conhecimentos que permeiem a formação técnica-profissional dos envolvidos. Essa conexão na escala local é mais importante ainda, tendo em vista as limitações das gestões públicas dos municípios em promover o desenvolvimento técnico-profissional dos seus colaboradores.

Entre esses colaboradores encontram-se os profissionais nas áreas da saúde em âmbito municipal. Esses profissionais, devido às restrições em seu processo de formação e qualificação ao longo das atuações diárias, que envolvem fatores financeiros e estruturais dos órgãos públicos, tendem a ter dificuldades na execução de seus serviços de acompanhamento e monitoramento da vigilância em saúde dos municípios. Inserir capacitações a esses profissionais, é algo primordial para preencher essa lacuna de conhecimento.

Um setor muito importante da estrutura da saúde dos municípios é o programa de agentes comunitários de saúde (PACS), que foi criado em 1990 e teve como objetivo fortalecer o Sistema Único de Saúde (SUS) e auxiliar o processo de transformação da estrutura dos serviços de saúde (NASCIMENTO; CORREA, 2008). Esse objetivo leva a incluir um planejamento e oferta de serviços no contexto epidemiológico, com a análise dos fatores envolvidos que estão correlacionados a um risco a saúde, e como podem ocorrer ações de intervenções para garantia da promoção da saúde da população (SAMPAIO; LIMA, 2002).

Esses agentes de saúde têm papel fundamental no processo de construção da coletividade, no que diz respeito a saúde pública, pois fazem parte de uma reestruturação da reorganização da atenção à saúde, o que os coloca como um recurso potencial nas ações de promoção e prevenção da saúde pública local (CAMPOS, 2003). É fato que os agentes de saúde percebem dificuldades dessa sua inserção no processo estratégico de atenção à saúde, tendo em vista que muitas vezes os profissionais da saúde como médicos e enfermeiros são mais destacáveis no contexto de atuação das Secretárias de Saúde (MARZARI et al., 2011).

Dentro de possíveis temas comuns na rotina diária dos vigilantes em saúde, está a temática sobre os morcegos, que são um grupo animal comumente presente na área urbana e que podem estar associados a problemas de saúde, estética e poluição sonora, quando usam as construções urbanas como abrigos (SILVA; ANACLETO, 2011). Esses animais por possuírem a capacidade de voo, hábitos noturnos, permanência em repouso de cabeça para baixo e a variabilidade de nicho alimentar, incluindo os morcegos hematófagos, que se alimentam de sangue, são colocados em uma associação com trevas, mortes e espíritos malignos (ALVES, 
1999), além de serem transmissores de doenças, que incluem a doença de chagas, histoplasmose, raiva (FABIAN, 1991; OLIVEIRA et al., 2006; CARVALHO et al., 2008), bem como, podem portar outros tipos de vírus, como a hantavirose (SABINO-SANTOS et al., 2020) e os coronavírus (GÓES et al., 2016).

Morcegos são um grupo animal de alta diversidade no Brasil, com mais de 180 espécies descritas atualmente (NOGUEIRA et al., 2014; FEIJÓ et al., 2015), e uma diversidade de papéis ecológicos positivos, que incluem espécies polinizadoras, dispersoras de sementes, presas e reguladoras de outras populações animais (BOYLES et al., 2011).

A presença de morcegos em área urbana está correlacionada com uma série de variáveis, que incluem a expansão urbana e agrícola que consequentemente suprime áreas naturais, onde extingue espécies e condicionam outras a uma adaptação a áreas alteradas (PACHECO et al., 2010). Outra variável é o planejamento urbano inadequado, que condiciona a presença dos morcegos frugívoros e insetívoros (HARMANI et al., 1996; FENTON, 1997), como a presença de plantas frutíferas (NOVAES e NOBRE, 2009) e iluminação pública que atrai insetos (RYDELL; RACEY, 1995). Soma se a isso, as construções urbanas mal planejadas ou estruturadas, que criam espaços para abrigo das espécies de morcegos.

Nesse contexto, muitas vezes as instituições públicas de ensino possuem corpo de trabalho técnico-profissional capacitado, que permitem a qualificação não somente dos seus alunos regularmente matriculados, mas que podem quebrar as barreiras do território escolar e promover ações de capacitação para o público externo, de forma a garantir a resolução do problema, que é a baixa inserção de conexões entre o meio acadêmico e os órgãos de atuação local.

Entre essas instituições, estão as de ensino Federal, mais especificamente os Institutos Federais, que possuem entre os seus objetivos essa vertente, conforme a Lei 11.892 de 29 de dezembro de 2008 , em seu Art. $7^{\circ}$, Inciso IV:

\footnotetext{
Desenvolver atividades de extensão de acordo com os princípios e finalidades da educação profissional e tecnológica, em articulação com o mundo e os segmentos sociais, e com ênfase na produção, desenvolvimento e difusão de conhecimentos científicos e tecnológicos.
}

Dessa forma, o Instituto Federal, denota sua presença e interesse em partilhar dos conhecimentos de seus profissionais no processo de construção da cidadania e melhoramento ambiental, uma vez, nesse caso específico, que os profissionais capacitados serão atuantes no processo de disseminação de procedimentos e informações corretas sobre um grupo animal de interesse clínico, e tão importante para manutenção positiva dos ciclos ecossistêmicos. 
Com esse enfoque, o objetivo dessa pesquisa foi promover a conexão escola-sociedade com a realização de um processo de capacitação técnico-científica de profissionais da saúde do município de Pontes e Lacerda, Mato Grosso, Brasil sobre a temática morcegos.

\section{Metodologia}

O processo de capacitação foi desenvolvido no município de Pontes e Lacerda, Mato Grosso, Brasil (Figura 1). O município possui população estimada de 45.436 pessoas em uma área territorial de $8.567,455 \mathrm{~km}^{2}$ (IBGE, 2019).

Figura 1 - Localização do município de Pontes e Lacerda na Fronteira Oeste do estado de Mato Grosso, Brasil

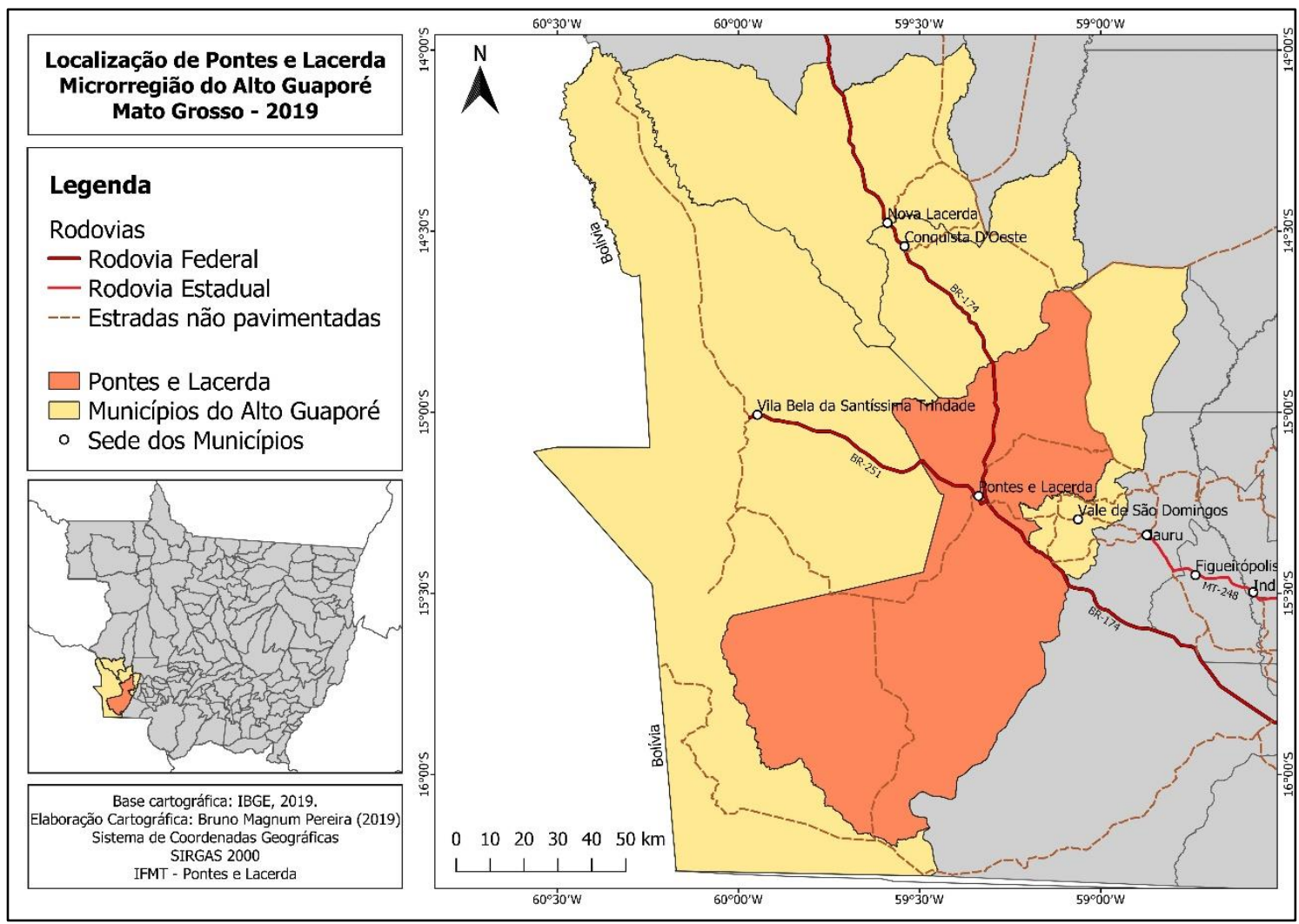

Fonte: Geógrafo Bruno Magnum Pereira (2019).

A Prefeitura Municipal conta com um Departamento de Vigilância em Saúde, com mais de 30 agentes de saúde atuantes no processo de orientação e fiscalização da população do município.

Para realização da capacitação, as ações foram divididas em etapas específicas (Figura 2), de forma a atingirem os resultados propostos: 
Figura 2 - Organograma com as etapas do processo de capacitação dos agentes de saúde do município de Pontes e Lacerda, Mato Grosso, Brasil

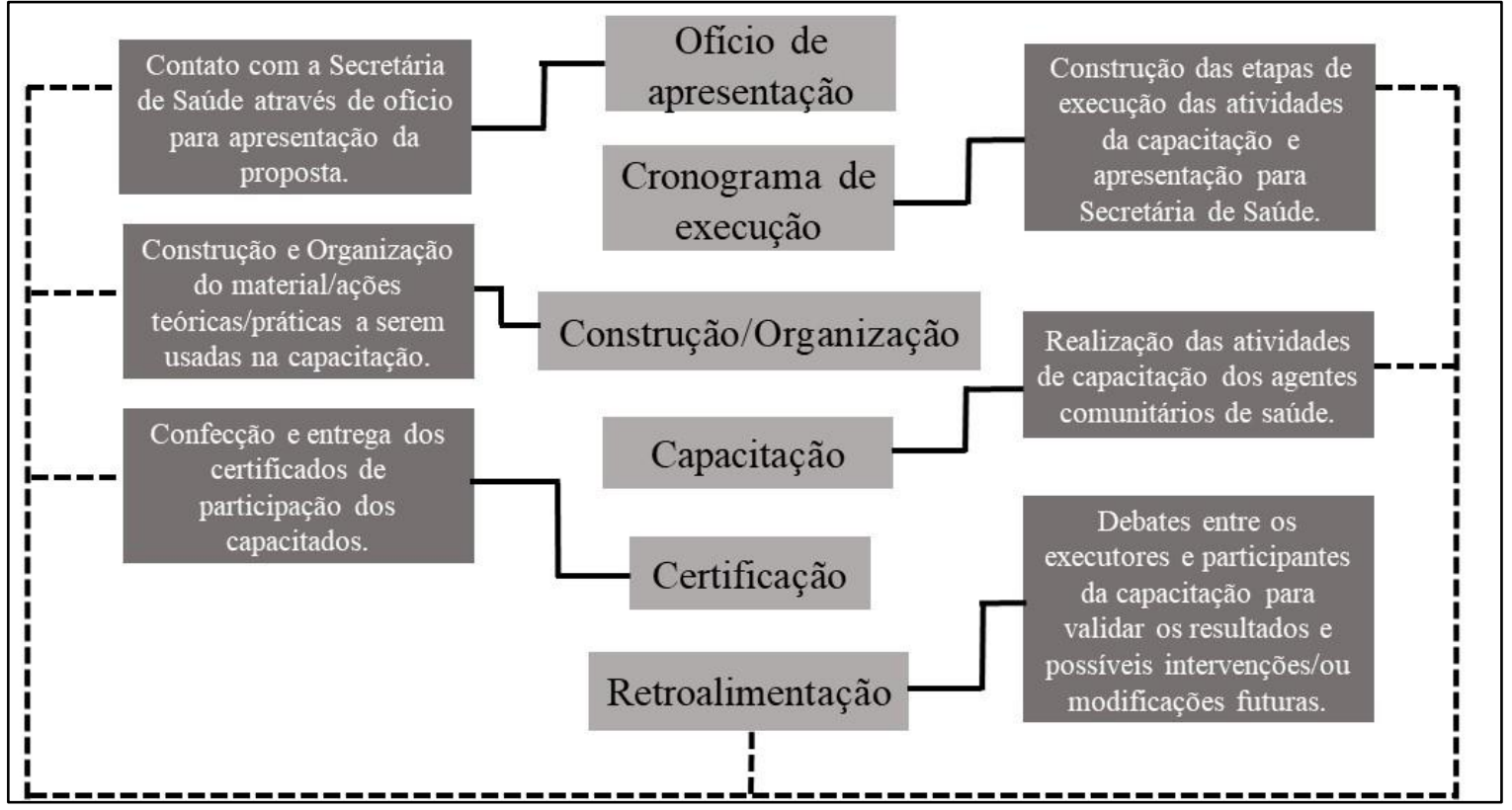

Fonte: os autores.

a) Oficialização junto a Secretária Municipal de Saúde de Pontes e Lacerda: foi realizado o contato com os responsáveis pela Secretária Municipal de Saúde, de forma a expor a proposta da capacitação aos agentes de saúde do município. Dessa forma foi realizada a quantificação de agentes e possíveis datas para realização do processo de capacitação.

b) Cronograma de execução: após autorização, foi preparado um cronograma de atividades a serem desenvolvidas juntos aos agentes de saúde do município, de maneira a encaixar em um contexto que não prejudicasse as atividades da Secretária Municipal de Saúde.

c) Capacitação teórica e prática: as ações dessa etapa ocorreram em momentos distintos, iniciando com a realização de uma capacitação teórica em sala de aula, que abordou os temas: 1) histórico dos morcegos; 2) importância ecológica; 3) importância epidemiológica; 4) estudos com morcegos; 5) equipamentos e métodos para contenção urbana. A parte prática, foi realizada no Laboratório de Biologia e na área externa do IFMT, Pontes e Lacerda, com as atividades: 1) materiais de campo; 2) identificação de morcegos; 3) formalização e fixação de morcegos; 4) coleção úmida, e posteriormente foram realizadas atividades de manipulação de captura de morcegos, para colocar em prática os aprendizados teóricos.

d) Certificação e finalização: os agentes de saúde participantes foram certificados como capacitados no processo de introdução a identificação, capturas e manipulação de morcegos urbanos, onde foi realizado uma mesa redonda com os participantes, para mensurar o 
impacto dos conhecimentos adquiridos no processo de capacitação.

Dentro desse contexto, ao final, foi possível verificar o impacto do desenvolvimento do projeto, no processo de capacitação dos agentes de saúde do município de Pontes e Lacerda.

\section{Resultados e Discussão}

A possibilidade da execução da conexão escola-sociedade, só é possível, quando as partes envolvidas estão dispostas a conjugar positivamente, abrindo espaços para inserções de atividades como processos de capacitações. A Secretária Municipal de Saúde de Pontes e Lacerda reflete bem essa positividade na conexão entre instituições, tendo em vista, que cederam a possibilidade para a realização da capacitação de seus agentes de saúde pelo corpo técnico-pesquisador do Instituto Federal de Mato Grosso, campus Pontes e Lacerda. Ações de capacitação técnica de agentes de saúde são uma realidade no Brasil, porém, estão limitados muitas vezes a ações em Universidades e cooperação com as agências de saúde (PEDROSA et al., 2011; CARDOSO et al., 2011; ARAÚJO et al., 2015).

Um ponto fundamental nesse tipo de atividade, está relacionado à organização de organograma prévio para não prejudicar as atividades rotineiras dos agentes de saúde. Deve também buscar dentro da construção desse tipo de ação, a realização de um processo formativo e modificador, de forma a não se tornar um evento não significativo para a incorporação de conhecimentos técnicos-científicos aos agentes de saúde. Participaram da capacitação 24 agentes de saúde, que com a autorização da Secretária de Saúde do município iniciaram as atividades teóricas abordando os morcegos.

Na parte teórica foi abordado aspectos históricos dos morcegos, que permitiram aos agentes de saúde conhecer um pouco sobre esses animais. Isso é importante considerando a temática dessa capacitação, uma vez, que as pessoas não possuem contato direto com morcegos e os enxergam como animais perigosos e misteriosos, geralmente associado a trevas, espíritos e morte (SILVA et al., 2013). Dentro desse contexto histórico, os agentes de saúde compreenderam os aspectos que conduziram os morcegos a um processo evolutivo gradual, bem como, aspectos da estrutura física e fisiológica desses animais (ADAMS; PEDERSEN, 2013). Também foi possível quebrar mitos associados e conhecer a diversidade de espécies de morcegos, tendo em vista, que boa parte dos agentes de saúde correlacionavam a existência de um baixo número de espécies, o que reflete a falta de conhecimento, considerando que a diversidade de espécies de morcegos no Brasil, já ultrapassam 180 espécies, com mais de 74 registros para o estado de Mato Grosso (BERNARD et al., 2011). 
Quando abordados os aspectos ecológicos dos morcegos, os agentes de saúde puderam compreender a diversidade de hábitos alimentares associados a esses animais, que os colocam como nectarívoros, frugívoros, carnívoros, hematófagos, pscívoros e insetívoros (BORDIGNON; FRANÇA, 2002; FLEMING et al., 2009; BARROS et al., 2014; PEÑADOMENE et al., 2014; ORLANDO et al., 2019). Essa diversidade de nichos alimentares, permitem que morcegos façam a polinização de uma diversidade de espécies de plantas, bem como dispersem seus frutos, além de controlarem populações de insetos e outros animais, ou seja, executando um amplo papel de manutenção positivo de ciclos ecossistêmicos fundamentais para restauração florestal e sua permanência. Além disso, os serviços ecossistêmicos prestados pelos morcegos beneficiam os seres humanos, que utilizam uma diversidade de frutos polinizados e dispersos pelos morcegos (LUZ et al., 2015), e sofrem menos impactos causados por insetos, quando há a presença de morcegos insetívoros (BOYLES et al., 2011).

Porém, os agentes de saúde relataram a preocupação com os aspectos epidemiológicos associados aos morcegos com enfoque na transmissão do vírus da raiva, e que os morcegos hematófagos são os maiores vilões na propagação desse vírus. Esse pensamento tem uma íntima associação com informações midiáticas, que muitas vezes trazem de forma sensacionalista informações sobre surtos relacionados a ataque de morcegos hematófagos em humanos (ROSA et al., 2006).

Os conceitos preestabelecidos de maneira equivocada pelos agentes de saúde sobre riscos epidemiológicos foram revertidos na abordagem do conteúdo teórico, onde foi possível a compreensão dos aspectos reais sobre as questões de risco epidemiológico associados aos morcegos. Uma delas, é que a transmissão do vírus da raiva não é uma exclusividade de morcegos hematófagos, que por sinal, possuem apenas três espécies com ocorrência nas Américas (REIS et al., 2007) dentro da diversidade de espécies de morcegos conhecidas mundialmente. $\mathrm{O}$ vírus da raiva é um vírus que ocorre em mamíferos, de qualquer espécie, com ocorrência mais comum em morcegos, roedores e cachorros silvestres, além da fauna doméstica, que incluem felinos, canídeos e bovinos (BAER, 2007). Os agentes de saúde, também puderam compreender, que os morcegos são hospedeiros definitivos, assim como os humanos, ou seja, quando o morcego é contaminado, o vírus da raiva evolui até a morte do animal. Além disso, a capacitação teórica permitiu a compreensão de que além do vírus da raiva, os morcegos estão na cadeia da transmissão de outras doenças, como a histoplasmose, hantavirose, ebola e possivelmente a versão recém descoberta de coronavírus (LU et al., 2020), 
que desencadeou uma pandemia no globo terrestre. Isso denota a importância de medidas profiláticas em ambiente urbano, como a vacinação antirrábica anual dos animais domésticos.

Para os agentes de saúde, estudar morcegos era uma questão de associação com transmissão de doenças, o que pode ser modificado com a capacitação e a compreensão da diversidade de estudos realizados com morcegos, que vão desde o contexto de identificar o inventário da diversidade de espécies em uma localidade, bem como, estudo dos papéis ecológicos, valoração de serviços ecossistêmicos, sensibilização ambiental e resposta a efeitos diversos, como fragmentação florestal, urbanização ou toxicidade nos morcegos. As características associadas aos morcegos reforçam a importância de explorar outras temáticas associadas a esses animais, de forma a não correlacionar sempre o morcego como o vilão, e que sim, é possível conviver com eles como relatado em outros estudos (AYIVOR et al., 2017), onde populações humanas convivem harmoniosamente com a presença dos morcegos.

Os agentes de saúde ainda puderam conhecer os materiais associados a manipulação dos morcegos, principalmente, com enfoque na contenção urbana. Isso é muito importante nas atividades rotineiras dos agentes, uma vez, que o uso de Equipamentos de Proteção Individual, que incluem luva de raspa de couro, rede de neblina, sacos de contenção e puças, são fundamentais para qualquer ação que envolva morcegos. Além disso, manter a aplicação de vacinas de pré-exposição para raiva, é muito importante para evitar possíveis contaminações dos agentes de saúde, uma vez, que os incidentes com possíveis focos de transmissão, são comuns dentro das áreas urbanas (MOREIRA; LIMA, 2013).

Uma segunda etapa da capacitação envolveu a parte prática, com ações voltadas para os agentes de saúde poderem fixar conhecimento, e poder incorporar as ações correlacionadas com morcegos em sua rotina de trabalho. Isso foi muito significante na capacitação, uma vez que esses profissionais muitas vezes têm pouco conhecimento prático, porém são fundamentais no processo de educação popular em saúde (ÁVILA, 2011). Dessa forma, em laboratório, os agentes de saúde visualizaram e manipularam morcegos coletados (Figura 3), que ficam armazenados na coleção úmida da instituição, e são importantes no processo de ensinoaprendizagem, como já experimentado por outras pesquisas com outros grupos animais (SILVA et al., 2018). As coleções permitiram o contato direto com o objeto de estudo, tendo em vista que a visualização de morcegos na ativa é difícil, pelo seu hábito de estar voando em movimentos rápidos, ou escondidos em espaços escuros no interior das construções urbanas. 
Figura 3 - Atividade prática em laboratório com os agentes de saúde do município de Pontes e Lacerda, Brasil

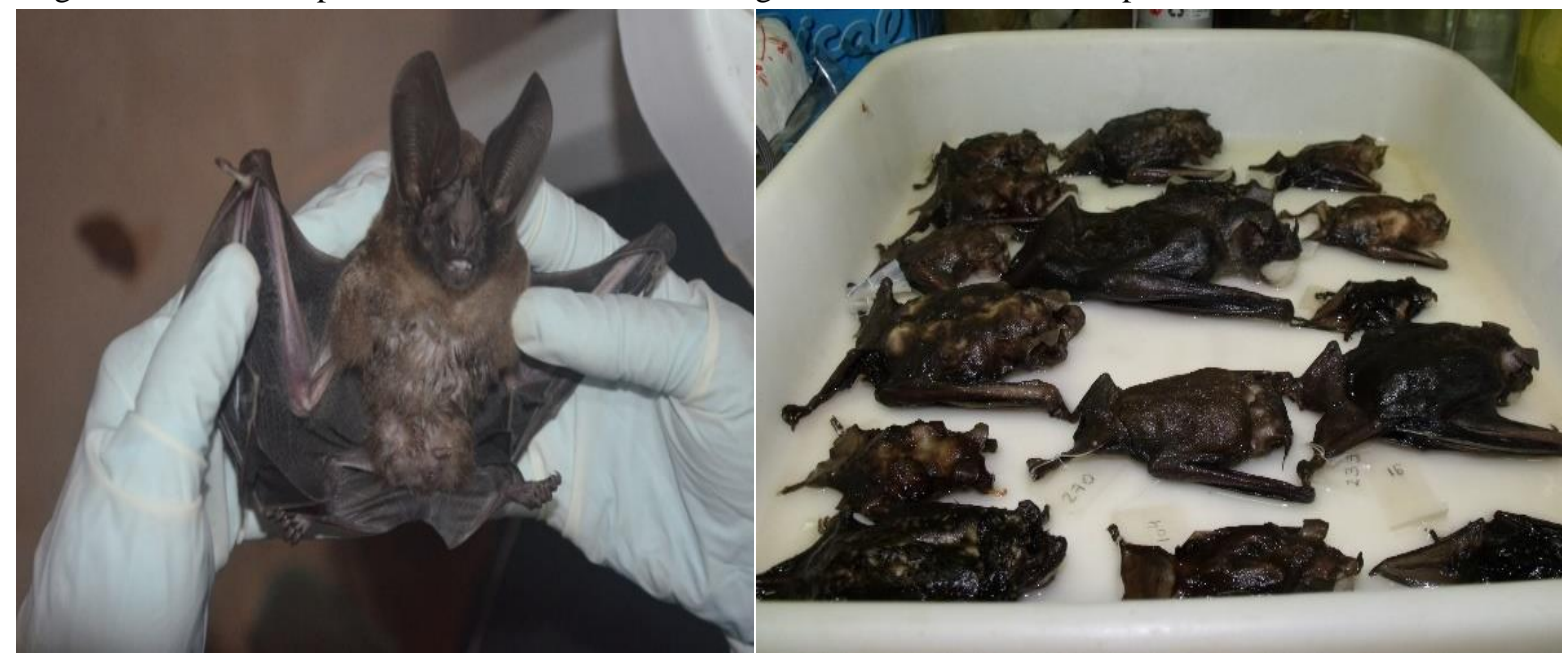

Fonte: Os autores.

A manipulação de morcegos permitiu também a capacitação para os agentes de saúde estarem identificando os diferentes tipos de espécies de morcegos que ocorrem em ambiente urbano, inclusive os de hábitos hematófagos. Dessa forma, os agentes de saúde podem orientar corretamente a população ou até intervirem quando se depararem com algum morcego em sua residência, uma vez, que muitas vezes, esses profissionais não são capacitados para esse tipo de atuação, e sim para somente fazerem o registro documental da ocorrência de possíveis animais, como ratos, pombos, cobras e morcegos (FONSECA et al., 2018). Outra ação aprendida, foi a compreensão do processo de coleta de morcegos em ambiente urbano para possíveis análises laboratoriais, onde espécimes com indício de algum tipo de contaminação são mortos com inalação anestésica, para então serem conduzidos para laboratórios específicos, que irão investigar e formular o possível diagnóstico, como é o caso realizado quando a suspeita de contaminação do morcego pelo vírus da raiva (ALMEIDA et al., 2015).

Para finalizar, os agentes de saúde aprenderam o processo de captura de morcegos por meio da montagem de redes de neblina que são usadas na captura. Essas redes são usadas em malhas diferentes também para captura de aves, e são o instrumento mais usado na amostragem e captura de morcegos (MARQUES et al., 2013). Os agentes foram orientados quanto ao uso das redes de neblina, que geralmente está associada a captura de grandes populações de morcegos em construções urbanas, ou amostragens eventuais em busca de uma possível espécie que possa oferecer risco, como a presença de morcegos hematófagos (Figura 4).

Figura 4. 
Figura 4 - Atividade prática, com a montagem de redes de neblina, usadas na captura de morcegos

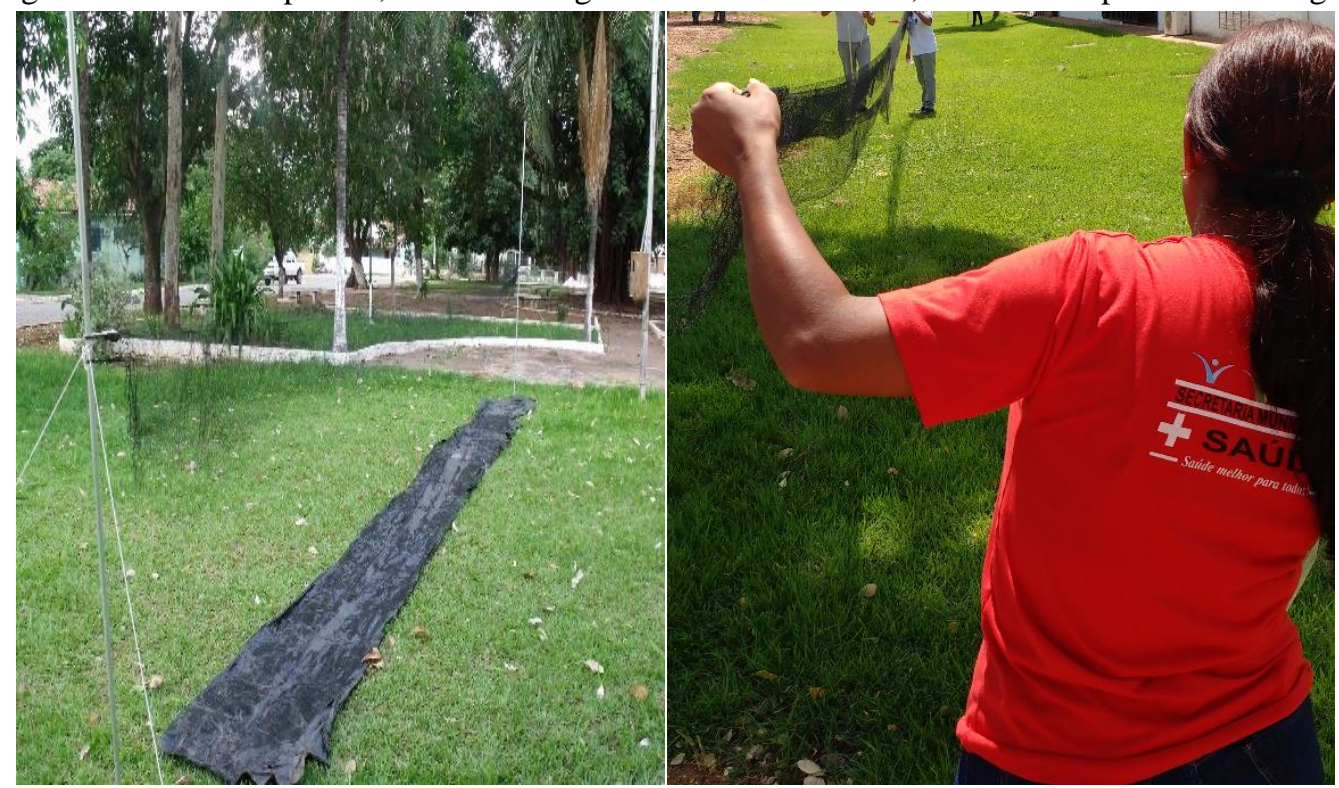

Fonte: os autores.

A finalização da capacitação contou ainda com uma retroalimentação com os participantes, que expuseram positividade quanto aos aprendizados incorporados. Qualificar os profissionais de uma instituição ou empresa é importante de várias maneiras, pois esses profissionais tendem a contribuir em maior escala com seu ambiente de trabalho (MOURÃO et al., 2014). Em nossa capacitação, apesar da certificação que os agentes de saúde recebem, ficou bem claro que o mais importante foi agregar conhecimento que permitem ampliar o rol de atuação no processo de atenção à saúde no município de Pontes e Lacerda, com a temática morcegos.

\section{CONSIDERAÇões FinAIS}

O processo de conexão escola-sociedade envolvidos por ações de extensões, é algo primordial para viabilizar a importância dos ambientes educacionais além da visão de atenderem somente alunos regulares em sala de aula.

Quando se aborda temáticas diversas que permitam acrescentar informações novas e inéditas no rol profissional de atuação de um setor fundamental para a atenção em saúde, o processo se torna significativo e de grande relevância.

Abordar a temática morcegos é sempre um desafio, uma vez que há poucos profissionais qualificados que direcionem didáticas inclusivas e que possam ser aplicadas de forma segura, e que sejam replicadas em outras escalas.

De forma geral, o contexto organizativo de capacitações com essa estrutura são modelos de replicação, bem como abrem espaço para discussões mais amplas que abordem 
outras linhas de atuação, como perpetuar o processo de sensibilização ambiental sobre os morcegos e diminuir o impacto da relação humano-morcego nos centros urbanos.

\section{REFERÊNCIAS}

ADAMS, Rick A.; PEDERSEN, Scott C. Bat evolution, ecology, and conservation. New York, Springer, 2013. https://doi.org/10.1007/978-1-4614-7397-8. Disponível em: https://link.springer.com/book/10.1007\%2F978-1-4614-7397-8. Acessado em: 10 jun. 2020.

ALMEIDA, Marilene Fernandes; ROSA, Adriana Ruckert; SODRÉ, Miriam Martos; MARTORELLI, Luzia Fátima Alves; NETTO, José Trezza. Fauna de morcegos (Mammalia, Chiroptera) e a ocorrência de vírus da raiva na cidade de São Paulo, Brasil. Veterinária e Zootecnia, v. 22, n. 1, p. 89-100, 2015. Disponível em: https://www.researchgate.net/profile/Marilene_Almeida/publication/294874306_FAUNA_DE MORCEGOS MAMMALIA CHIROPTERA E A OCORRENCIA DE VIRUS DA RA IVA_NA_CIDADE_DE_SAO_PAULO_BRASIL/links/56c4e60508ae7fd4625a48a0/FAUN A-DE-MORCEGOS-MAMMALIA-CHIROPTERA-E-A-OCORRENCIA-DE-VIRUS-DARAIVA-NA-CIDADE-DE-SAO-PAULO-BRASIL.pdf. Acessado em: 05 mar. 2020.

ALVES, Glaucia Morelli. Morcegos da fazenda Lageado: concepções dos moradores e riquezas de espécies em trilha ecológica. 1999. $61 \mathrm{f}$. Trabalho de conclusão de curso (Bacharelado em Ciências Biológicas) - Instituto de Biociências, Universidade Estadual Paulista, Botucatu, 1999.

ARAÚJO, Eliene Silva; JACOB-CORTELETTI, Lilian Cassia Bornia; ABRAMIDES, Dagma Venturini Marques; ALVARENGA, Kátia Freitas. Capacitação de agentes comunitários de saúde na área de saúde auditiva infantil: retenção da informação recebida. Revista CEFAC, v. 17, n. 2, p. 445-453, 2015. https://doi.org/10.1590/1982-0216201511913. Disponível em: https://www.scielo.br/scielo.php?script=sci_arttext\&pid=S151618462015000200445\&lng=pt\&tlng=pt. Acessado em: 04 abr. 2020.

ÁVILA, Maria Marlene Marques O programa de agentes comunitários de saúde no Ceará: o caso de Uruburetama. Ciência e Saúde Coletiva, v. 16, n. 1, p. 349-360, 2011. http://dx.doi.org/10.1590/S1413-81232011000100037. Disponível em: https://www.scielo.br/scielo.php?script=sci_arttext\&pid=S141381232011000100037\&lng=pt\&tlng=pt. Acessado em: 18 jun. 2020.

AYIVOR, Jesse S.; OHEMENG, Fidelia; LAWSON, Elaine Tweneboah; WALDMAN, Linda; LEACH, Melissa; NTIAMOA-BAIDU, Yaa. Living with bats: the case of ve Golokuati township in the Volta region of Ghana. Journal of Environmental and Public Health, p. 1-11, 2017. https://doi.org/10.1155/2017/5938934. Disponível em: https://www.hindawi.com/journals/jeph/2017/5938934/. Acessado em: 05 fev. 2020.

BAER, George M. The history of rabies. Rabies (Second Edition), p. 1-22, 2007. https://doi.org/10.1016/B978-012369366-2/50003-8. Disponível em: https://www.sciencedirect.com/science/article/pii/B9780123693662500038?via\%3Dihub. Acessado em: 12 jan. 2020. 
BARROS, Marília A. S.; PESSOA, Daniel M. A.; RUI, Ana Maria. Habitat use and seasonal activity of insectivorous bats (Mammalia: Chiroptera) in the grasslands of Southern Brazil. Zoologia, v. 31, n. 2, p. 153-161, 2014. https://doi.org/10.1590/S1984-46702014000200006. Disponível em: https://www.scielo.br/scielo.php?script=sci_arttext\&pid=S198446702014000200006\&lng=en\&nrm=iso\&tlng=en. Acessado em: 23 mar. 2020.

BERNARD, Enrico; TAVARES, Valéria da Cunha; SAMPAIO, Erica. Compilação atualizada das espécies de morcegos (Chiroptera) para a Amazônia Brasileira. Biota Neotropical, v. 11, n. 1, p. 35-46, 2011. https://doi.org/10.1590/S1676-06032011000100003. Disponível em: https://www.scielo.br/scielo.php?script=sci_arttext\&pid=S167606032011000100003\&lng=pt\&tlng=pt. Acessado em: 12 abr. 2020.

BORDIGNON, Marcelo O.; FRANÇA, Adriana O. 2002. Fish consumption by Noctilio leporinus (Linnaeu, 1758) in Guaratuba Bay, Southern Brazil. Chiroptera Neotropical, v. 8, n. 1, p. 148-150.

BOYLES, Justin G.; CRYAN, Paul M.; MCCRACKEN, Gary F.; KUNZ, Thomaz H. 2011. Economic importance of bats in agriculture. Science, v. 332, p. 41-42.

https://doi.org/10.1126/science.1201366. Disponível em: https://science.sciencemag.org/content/332/6025/41. Acessado em: 29 jun. 2020.

CAMPOS, Gastão Wagner de Souza. Saúde Paidéia. São Paulo: Editora Hucitec; 2003.

CARDOSO, Fátima Aparecida; CORDEIRO, Vitória Régia de Negreiros; LIMA, Daniele Barreto de; MELO, Bárbara de Caldas; MENEZES, Raquel Nobre Barreto de; MOULAZ, Ana Luiza Silva de; SÁ, Gabrielle Boff de; SOUZA, Adalgisa Vânia Fernandes de.

Capacitação de agentes comunitários de saúde: experiência de ensino e prática com alunos de enfermagem. Revista Brasileira de Enfermagem, v. 64, n. 5, p. 968-973, 2011.

https://doi.org/10.1590/S0034-71672011000500026. Disponível em:

https://www.scielo.br/scielo.php?script=sci_arttext\&pid=S0034-

71672011000500026\&lng=pt\&tlng=pt. Acessado em: 13 abr. 2020.

CARVALHO, Cristiano de; GONÇALVES, Juliano Ferreira; FRANCO, Rafael;

CASAGRANDE, Daiane K. A.; PEDRO, Wagner André; QUEIROZ, Luzia Helena.

Levantamento da fauna de chiroptera e ocorrência de vírus rábico em municípios da região de Araçatuba - SP. Veterinária e Zootecnia, Botucatu, v. 15, n. 2, p. 73, 2008. (Suplemento). Disponível em: https://repositorio.unesp.br/handle/11449/132990. Acessado em: 22 jan. 2020.

FABIAN, Marta E. Contribuição ao estudo da infecção de morcegos por hemoflagelados do gênero Trypanosoma Gruby, 1843. Caderno de Saúde Pública, v. 7, n. 1, p. 69-81, 1991.

https://doi.org/10.1590/S0102-311X1991000100006. Disponível em:

https://www.scielo.br/scielo.php?script=sci_arttext\&pid=S0102311X1991000100006\&lng=pt\&tlng=pt. Acessado em: 15 jan. 2020.

FEIJÓ, Anderson; ROCHA, Patrício Adriano da; ALTHOFF, Sergio Luiz. New species of Histiotus (Chiroptera: Vespertilionidae) from northeastern Brazil. Zootaxa, v. 4048, n. 3, p. 412-427, 2015. https://doi.org/10.11646/zootaxa.4048.3.4. Disponível em:

https://www.biotaxa.org/Zootaxa/article/view/zootaxa.4048.3.4. Acessado em: 15 jun. 2020. 
FENTON, M. Brock. Science and the conservation of bats. Journal of Mammalogy, v. 78, p.1, p. 1-14, 1997. https://doi.org/10.2307/1382633. Disponível em:

https://academic.oup.com/jmammal/article/78/1/1/872126. Acessado em: 14 mar. 2020.

FLEMING, Theodore H.; GEISELMAN, Cullen; KRESS, W. John. The evolution of bat pollination: a phylogenetic perspective. Annals of Botany, v. 104, n. 6, p. 1017-1043, 2009. https://doi.org/10.1093/aob/mcp197. Disponível em: https://academic.oup.com/aob/article/104/6/1017/184229. Acessado em: 25 jan. 2020.

FONSECA, Alysson Rodrigo; ROCHA, Bruna Fonseca; PEREIRA, Márcio Henrique; SILVA, Daniel Almeida; SOUSA, Fabrízio Furtado. Levantamento de ratos, morcegos, pombos e cobras pelo setor de vigilância ambiental do município de Divinópolis - MG. Hygeia Revista Brasileira de Geografia Médica e da Saúde, v. 14, n. 27, p. 41-55, 2018. https://doi.org/10.14393/Hygeia142704. Disponível em: http://www.seer.ufu.br/index.php/hygeia/article/view/38163. Acessado em: 23 abr. 2020.

GÓES, Luiz Gustavo Bentin; CAMPOS, Angélica Cristine de Almeida; CARVALHO, Cristiano de; AMBAR, Guilherme; QUEIROZ, Luzia Helena; CRUZ-NETO, Ariovaldo Pereira; MUNIR, Muhammad; DURIGON, Edison Luiz. Genetic diversity of bats coronaviruses in the Atlantic Forest hostspot biome, Brazil. Infection, Genetics and Evolution, v. 44, p. 510-513, 2016. https://doi.org/10.1016/j.meegid.2016.07.034. Disponível em: https://www.sciencedirect.com/science/article/pii/S1567134816303240?via\%3Dihub. Acessado em: 18 mar. 2020.

HARMANI, Necira M.S; SILVA, Mirian M.S.; HAYASHI, Mirian Mitsue. Controle de morcegos em áreas urbanas. Boletim do Instituto Pasteur 1(2): 37-43, 1996.

Instituto Brasileiro de Geografia e Estatística - IBGE. Instituo Brasileiro de Geografia e Estatística - IBGE, Cidades, Pontes e Lacerda. 2019. Disponível em https://cidades.ibge.gov.br/brasil/mt/pontes-e-lacerda/panorama. Acesso em: 10 maio 2020.

LU Roujian; ZHAO, Xiang; LI, Juan; NIU, Pehiua; YANG, Bo; WU, Honglong; WANG, Wenling; SONG, Hao; HUANG, Baoying; ZHU, Na; BI, Yuhai... TAN, Wenjie. Genomic characterisation and epidemiology of 2019 novel coronavirus: implications for virus origins and receptor binding. Lancet, v. 30, p. S0140-6736(20)30251-8, 2020.

http://doi.org./10.1016/S0140-6736(20)30251-8. Disponível em:

https://www.sciencedirect.com/science/article/pii/S0140673620302518?casa token=ovJ8cA3 N8O4AAAAA:NxtMsfyKr01ZKwXHRkqOUeVy16cdTyB1C3faFAB6I3Viyn0ghmuwdW9o VQS9U6-BfMz2KJJLBAEh. Acessado em: 25 mar. 2020.

LUZ, Júlia Lins; COSTA, Luciana de Moraes; ESBERARD, Carlos Eduardo Lustosa. Variação de recursos alimentares e abundância de morcegos em plantações de banana. Oecologia Australis, v. 19, p. 244-260, 2015. http://doi.org/10.4257/oeco.2015.1901.16. Disponível em: https://revistas.ufrj.br/index.php/oa/article/view/8336. Acessado em: 22 jun. 2020.

MARQUES, João Tiago; PEREIRA, Maria J. Ramos; MARQUES, Tiago A.; SANTOS, Carlos David; SANTANA, Joana; BEJA, Pedro; PALMEIRIM, Jorge M. Optimizing sampling design to deal with mist-net avoidance in Amazonian birds and bats. Plos One, v. 8, n. 9, p. e74505, 2013. https://doi.org/10.1371/journal.pone.0074505. Disponível em: 
https://journals.plos.org/plosone/article?id=10.1371/journal.pone.0074505. Acessado em: 30 jan. 2020.

MARZARI, Carla Kowalski; JUNGES, José Roque; SELLI, Lucilda. Agentes comunitários de saúde: perfil e formação. Ciência \& Saúde Coletiva, v. 16, sup. 1, p. 873-880, 2011. https://doi.org/10.1590/S1413-81232011000700019. Disponível em: https://www.scielo.br/scielo.php?script=sci_arttext\&pid=S1413-

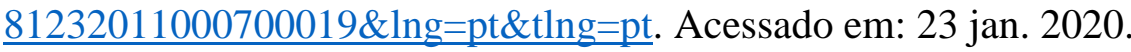

MOREIRA, Antônio Aguilar Marcos; LIMA, Monia Maia. Conduta dos profissionais de saúde pública frente ao atendimento antirrábico humano no município de Primavera do LesteMT. Revista de Epidemiologia e Controle de Infecção, v. 3, n. 4, p. 139-143, 2013. http://dx.doi.org/10.17058/reci.v3i4.4044. Disponível em:

https://online.unisc.br/seer/index.php/epidemiologia/article/view/4044. Acessado em: 24 fev. 2020.

MOURÃO, Luciana; MONTEIRO, Ana Cláudia Fernandes.; VIANA, Viviane Ribeiro. A influência do desenvolvimento profissional e da identificação organizacional na satisfação no trabalho. Dialnet, v. 45, n. 2, p. 198-208, 2014. Disponível em:

https://dialnet.unirioja.es/servlet/articulo?codigo=5633329. Acessado em: 29 mar. 2020.

NASCIMENTO, Elisabet Pereira Lelo; CORREA, Carlos Roberto da Silveira. O agente comunitário de saúde: formação, inserção e práticas. Caderno de Saúde Pública, Rio de Janeiro, v. 24, n. 6, p. 1304-1313, 2008. https://doi.org/10.1590/S0102-311X2008000600011. Disponível em: https://www.scielo.br/scielo.php?script=sci_arttext\&pid=S0102-

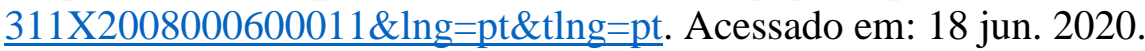

NOGUEIRA, Marcelo Rodrigues; LIMA, Isaac Passos de; MORATELLI, Ricardo; TAVARES, Valéria da Cunha; GREGORIN, Renato; PERACCHI, Adriano Lúcio. Checklist of brazilian bats, with comments on original records. Check List, v. 10, p. 4, p. 808-821, 2014. https://doi.org/10.15560/10.4.808. Disponível em: https://checklist.pensoft.net/article/18978/

NOVAES, Roberto Leonan; NOBRE, Carla Clarissa. Dieta de Artibeus lituratus (Olfers, 1818) em área urbana na cidade do Rio de Janeiro: frugivoria e novo registro de folivoria. Chiroptera Neotropical, v. 15, n. 2, p. 487-493, 2009. Disponível em: https://www.researchgate.net/profile/Roberto_Leonan_Novaes/publication/276145351_Dieta _de_Artibeus_lituratus_Olfers_1818_em_area_urbana_na_cidade_do_Rio_de Janeiro_Frugiv oria_e novo_registro_de_folivoria/links/5551458c08ae12808b3917b0/Dieta-de-Artibeuslituratus-Olfers-1818-em-area-urbana-na-cidade-do-Rio-de-Janeiro-Frugivoria-e-novoregistro-de-folivoria.pdf. Acessado em: 29 jun. 2020.

OLIVEIRA, Flávio de Mattos; UNIS, Gisela; SEVERO, Luiz Carlos. Microepidemia de histoplasmose em Blumenau, Santa Catarina. Jornal Brasileiro de Pneumologia, v. 32, n. 4, p. 375-378, 2006. https://doi.org/10.1590/S1806-37132006000400018. Disponível em: https://www.scielo.br/scielo.php?script=sci_arttext\&pid=S180637132006000400018\&lng=pt\&tlng=pt. Acessado em: 30 mar. 2020.

ORLANDO, Solón A.; PANCHANA, Vanessa F.; CALDERÓN, Joselyn L.; MUÑOZ, Olga S.; CAMPOS, Dédime N.; TORRES-LASSO, Pablo R.; ARCOS, Fabrizio J.; QUENTIN, 
Emmanuelle. Risck factors associated with attacks of Hematophagous bats (Desmodus rotundus) on cattle in Ecuador. Vector-Borne and Zoonotic Diseases, v. 19, n. 6, p. 407-413, 2019. https://doi.org/10.1089/vbz.2017.2247. Disponível em: https://www.liebertpub.com/doi/10.1089/vbz.2017.2247. Acessado em: 30 mar. 2020.

PACHECO, Susi M.; SODRÉ, Miriam; GAMA, A.R.; BREDT, Angelika; SANCHES, Edna M. Cavallini; MARQUES, Rosane V.; GUIMARÃES, M.M.; BIANCONI, Gledson. Morcegos urbanos: status do conhecimento e plano de ação para a conservação no Brasil. Chiroptera Neotropical, 16 (1): 629-647, 2010. Disponível em: https://www.researchgate.net/profile/Rosane_Marques/publication/272563542_Morcegos_Ur banos_Status_do_Conhecimento_e_Plano_de_Acao_para_a_Conservacao_no_Brasil/links/54 e9dae20cf2f7aa4d546cbc.pdf. Acessado em: 13 abr. 2020.

PEDROSA, Ivanilda Lacerda; LIRA, Gildeci Alves; OLIVEIRA, Bernadete de; SILVA, Maria do Socorro Moura Lins; SANTOS, Maria Betânea dos; SILVA, Eliete Alves da; FREIRE, Djacyr Magna Cabral. Uso de metodologias ativas na formação técnica do agente comunitário de saúde. Trabalho, Educação e Saúde, v. 9, n. 2, p. 319-332, 2011. https://doi.org/10.1590/S1981-77462011000200009. Disponível em: https://www.scielo.br/scielo.php?script=sci_arttext\&pid=S198177462011000200009\&lng=pt\&tlng=pt. Acessado em: 30 abr. 2020.

PEÑA-DOMENE, Marinés de La; MARTÍNEZ-GARZA, Cristina; PALMAS-PÉREZ, Sebastián; RIVAS-ALONSO, Edith; HOWE, Henry F. Roles of birds and bats in early Tropical-forest restoration. Plos One, v. 9, n. 8, p. 1-6, 2014. https://doi.org/10.1371/journal.pone.0104656. Disponível em: https://journals.plos.org/plosone/article?id=10.1371/journal.pone.0104656. Acessado em: 21 fev. 2020.

REIS, Nélio Roberto; PERACCHI, Adriano Lúcio; PEDRO, Wagner A.; LIMA, Isaac Passos de. Morcegos do Brasil. Londrina, Eduel, 2007.

SAMPAIO, Luis Fernando Rolim; LIMA, Pedro Gilberto Alves de. Apoio ao Programa Saúde da Família. São Paulo, BIREME/OPAS/OMS, 2002. Disponível em: http://files.bvs.br/upload/M/2002/Sampaio_Apoio_Programa.pdf acessado em 30 jun. de 2020.

ROSA, Elisabeth S. T.; KOTAIT, Ivanete; BARBOSA, Taciana F. S.; CARRIERI, Maria L.; BRANDÃO, Paulo E.; PINHEIRO, Amiraldo S.; BEGOT, Alberto L.; WADA, Marcelo Y.; OLIVEIRA, Rosely C. de; GRISARD, Edmundo C.; FERREIRA, Márcia; LIMA, Reynaldo J. da Silva; MONTEBELLO, Lúcia; MEDEIROS, Daniele B. A.; SOUSA, Rita C. M.; BENSABATH, Gilberta; CARMOS, Eduardo H.; VASCONCELOS, Pedro F. C. Battransmitted human rabies outbreaks, Brazilian Amazon. Emerging Infectious Diseases, v. 12, n. 8, p. 1197-1202, 2006. https://doi.org/10.3201/1208.050929. Disponível em: https://wwwnc.cdc.gov/eid/article/12/8/05-0929_article. Acessado em: 23 maio 2020.

RYDELL, Jens; RACEY, Paul A. Street lamps and the feeding ecology of insectivorous bats. Zoological Symposium, v. 67, p. 291-307, 1995.

SABINO-SANTOS JR, Gilberto; FERREIRA, Francimeire Fernandes; SILVA, David José da; MACHADO, Danilo Melo; SILVA, Sérgio Gomes da; SÃO BERNARDO, Christine Steiner; 
FILHO, Manoel dos Santos; LEVI, Taal; FIGUEIREDO, Luiz Tadeu Moraes; PERES, Carlos A.; BRONZONI, Roberta Vieira de Morais; CANALE, Gustavo Rodrigues. Hantavirus antibodies among phyllostomid bats from the arc of deforestation in southern Amazonia, Brazil. Transboudary and Emerging Diseases, p. 67, v. 3, p. 1045-1051, 2020.

https://doi.org/10.111/tbed.13442. Disponível em: https://onlinelibrary.wiley.com/doi/abs/10.1111/tbed.13442. Acessado em: 15 abr. 2020.

SILVA, Sérgio Gomes da; ANACLETO, Teresa Cristina Silveira. Diversidade de morcegos entre áreas com diferente grau de alteração na área urbana do município de Nova Xavantina, MT. Chiroptera Neotropical, v. 17, n. 1, p. 191-195, 2011. Disponível em: https://www.bvsvet.org.br/vetindex/periodicos/chiroptera-neotropical/17-(2011)-2/diversidade-de-morcegosentre-areas-com-diferente-grau-de-alteracao-na/. Acessado em: 25 maio 2020.

SILVA, Sérgio Gomes da; MANFRINATO, Márcia Helena Vargas; ANACLETO, Teresa Cristina da Silveira. Morcegos: percepção dos alunos do ensino fundamental $3^{\circ}$ e $4^{\circ}$ ciclos e práticas de educação ambiental. Ciência e Educação Bauru, v. 19, n. 4, p. 859-877, 2013. https://doi.org/10.1590/S1516-73132013000400006. Disponível em: https://www.scielo.br/scielo.php?script=sci_arttext\&pid=S151673132013000400006\&lng=pt\&tlng=pt. Acessado em: 15 abr. 2020.

SILVA, Sérgio Gomes da; FERREIRA, Francimeire Fernandes; SOUZA, Marco Rodrigo de; JARDIM, Larrisa Ferraz Bedôr. A taxidermia como estratégia de motivação à prática educacional-científica de futuros professores. Revista Prática Docente, v. 3, n. 1, p. 208-216, 2018. http://doi.org/10.23926/RPD.2526-2149.2018.v3.n1.p208-216.id182. Disponível em: http://periodicos.cfs.ifmt.edu.br/periodicos/index.php/rpd/article/view/182. Acessado em: 18 mar. 2020.

Recebido em: 9 de julho de 2020.

Aprovado em: 8 de outubro de 2020. 